\title{
Water-holding by dietary fibre in vitro and its relationship to faecal output in $\operatorname{man}^{1}$
}

\author{
ALISON M. STEPHEN, AND J. H. CUMMINGS \\ From the MRC Dunn Clinical Nutrition Centre, Addenbrookes Hospital, Cambridge
}

SUMMARY The in vitro water-holding properties of 17 dietary fibre preparations, mainly food materials, bulk laxatives, and gel-forming polysaccharides, have been measured. Water uptake was measured by a centrifugation technique and also by a new method using sacs of dialysis tubing containing the material, immersed in simulated gut contents. The centrifugation technique could not be applied to gel-forming polysaccharides but the methods gave broadly similar results for other materials $(r=0.85)$. The gel-forming polysaccharides in general held more water than the food fibres. Studies of matched pairs of materials which differed only slightly in chemical composition suggested that the presence of charged groups on the molecule encouraged water uptake. In the food materials water uptake was related to uronic acid content $(r=0 \cdot 87)$. Materials ground to a smaller particle size increase their water holding but this effect was small $(+28 \%)$. The hypothesis that dietary fibre increases faecal bulk by virtue of its ability to hold water was tested by comparing the in vitro water-holding capacity of eight of the fibres with the changes they had produced when fed to human volunteers under controlled conditions. Of these materials pectin had the greatest water-holding capacity $(56.2 \mathrm{~g}$ water/g material) but produced the smallest change in faecal weight $(19 \%)$, while bran had the lowest water-holding $(4 \cdot 2 \mathrm{~g} / \mathrm{g})$ and the largest faecal weight changes $(117 \%)$. Overall an inverse relationship $(r=0.88)$ between water-holding and faecal bulking was found, suggesting that dietary fibre does not exert its effect on faecal weight simply by retaining water in the gut.

One of the best established properties of dietary fibre is its ability to increase faecal output in man. The association of a large faecal output with a low incidence of disease of the large bowel has been noted by Burkitt and others (Burkitt, 1971; Trowell, 1972) who suggest that an adequate intake of dietary fibre is essential to protect against these diseases. How dietary fibre brings about changes in bowel habit is unknown, although it is widely felt that the capacity of dietary fibre to take up and hold water is important (Bastedo, 1935; Tainter and Buchanan, 1954; Eastwood, 1973). This particular characteristic of dietary fibre has been measured by a wide variety of methods (Klecker, 1931; Blythe et al., 1949; Berger, 1953; Monaco and Dehner, 1955; McConnell et al., 1974) and the results obtained used to recommend certain materials as faecal bulking agents (Ivy and Isaacs, 1938; Ireson and Leslie, 1970).

These in vitro techniques for measuring water uptake have not been adequately examined in terms

${ }^{1}$ Work performed by A.M.S. in part fulfilment for the Diploma in Nutrition, University of Cambridge.

Received for publication 21 February 1979 of their ability to predict what actually happens to faecal bulk in man. In addition, none is universally applicable to dietary fibre, in particular to both food fibre, gel-forming polysaccharides such as pectin and guar gum and plant derivatives like ispaghula.

We have therefore developed a different method of measuring water uptake by dietary fibre in which the fibre is placed in a small sack of dialysis tubing. We have compared results obtained by this method with the conventional centrifugation technique of McConnell et al. (1974) and contrasted the results from both methods with human colonic responses obtained when some of these fibres were fed under controlled conditions to man.

\section{Methods}

PLANT MATERIALS STUDIED

The following 17 fibre-containing materials were studied: $\alpha$ cellulose, sodium carboxymethyl cellulose (SCMC), locust bean gum, guar gum, $\lambda$ carrageenan, $\mathrm{K}$ carrageenan, pectin, Isogel, Normacol Special, Prewett's wheat bran, Allinson's bran plus, RHM 
bran, carrot fibre, cabbage fibre, apple fibre, potato pulp, and bagasse.

SCMC, locust bean gum, and the carrageenans were all supplied as fine powders by Unilever Ltd., Bedford. Cellulose was from Sigma. Isogel and Normacol Special were proprietary brands manufactured by Allen \& Hanbury's and Norgine respectively. Guar gum was provided by Hercules Powder Co. Kent, and pectin was Bulmer's Firmagel. Prewett's wheat bran and Allinson's bran plus were bought locally. RHM bran, carrot, cabbage, and apple were the material fed in metabolic studies conducted in this laboratory and prepared as described by Cummings et al. (1978). In this process the dried plant material is extracted with $85 \%$ methanol then acetone to remove free sugars, lipids, and pigments, etc. Potato pulp powder was provided by Unilever and the bagasse was that used in studies reported by Walters et al. (1975).

The moisture content of each material was determined by heating about $5 \mathrm{~g}$ to constant weight in an oven at $100^{\circ} \mathrm{C}$. Materials were ashed at $500^{\circ} \mathrm{C}$, residual organic matter being destroyed using concentrated nitric acid.

For the initial tests, materials were used as provided irrespective of particle size but, when relating water uptake and retention to chemical composition, this was controlled, as it is believed to affect waterholding properties (Kirwan et al., 1974).

For comparison of water uptake at two particle sizes, the fibre preparations were sieved for 30 minutes in an Endecott sieve shaker. Material of particle size 710-1000 $\mu \mathrm{m}$ was compared with that of size $75-150 \mu \mathrm{m}$, obtained by removing some of that retained in the $710-1000 \mu \mathrm{m}$ sieve, grinding it using the grinding attachment of a Kenwood Chef mixer, and resieving. Bran was ground on a Braun Multimix MX32.

MEASUREMENT OF WATER HOLDING

Two methods were used.

Centrifugation method (McConnell et al., 1974)

In this method $0.5 \mathrm{~g}$ of material was weighed into a $50 \mathrm{ml}$ centrifuge tube, to which was added $25 \mathrm{ml}$ simulated ileal fluid. Tops were placed on securely and the tubes rotated gently for 24 hours at $37 \cdot 5^{\circ} \mathrm{C}$. The tubes were then centrifuged for one hour at $14000 \mathrm{~g}$ and $20^{\circ} \mathrm{C}$, the supernatant discarded, and the weight of fluid retained calculated per gram of dry material.

\section{Dialysis method}

Small bags were made from $10 \mathrm{~cm}$ lengths of 20/32 Visking tubing and were tied at one end with cotton. Into each bag was weighed approximately $50 \mathrm{mg}$ of the material to be tested, the other end tied, and the bag reweighed. The bag was then placed in a $250 \mathrm{ml}$ conical flask and $100 \mathrm{ml}$ of test solution was added.

The test solution was designed to simulate the ionic composition and strength of the contents of the terminal ileum and right colon in man (Phillips and Giller, 1973) and had the following composition $(\mathrm{mmol} / \mathrm{l})$ : sodium 130 , potassium 10 , calcium 2 , bicarbonate 40, chloride 104 and urea $4 \mathrm{mmol} / \mathrm{l}$. $247 \mu \mathrm{mol} / 1$ Thimerosal (Sigma) was added to prevent bacterial growth and the solution brought to $\mathrm{pH} 6.8$ using $6 \mathrm{~mol} / 1 \mathrm{HCl}$. The osmolarity was $265 \mathrm{mosmol} / 1$. Each flask was covered and placed in an orbital incubator at $37 \cdot 5^{\circ} \mathrm{C}$. After one hour the bags were checked to ensure a good distribution of contents. At 24 and 48 hours the bags were removed, blotted with tissue, and weighed in a closed container. At 48 hours the test solution was changed to one of osmolarity 315 mosmol/1 made by adding $42 \mathrm{~g} / 1$ of polyethylene glycol 4000 (BDH) to the simulated gut fluid. Preliminary studies showed this to be the appropriate weight of PEG, although it is considerably less than expected from the given molecular weight. After an additional 24 hours the bags were again reweighed. Controls for this procedure were empty bags weighed at each time interval. The weight gain of these bags was subtracted from that of the fibrecontaining bags.

The water-holding ability for each fibre preparation was calculated as the weight of water held per gram of dry material. For each method the tests were carried out in triplicate.

\section{HUMAN STUDIES}

Of the materials used in this study eight had been used previously in controlled human metabolic studies investigating the effects of dietary fibre on bowel function. These were carrot, cabbage, apple, guar, RHM bran (Cummings et al., 1978), bagasse (Walters et al., 1975), Isogel (Greenberg, 1977), and pectin (Cummings et al., 1979). The reported changes in faecal weight induced by these materials in man have been compared with their in vitro water holding capacity.

\section{Results}

The composition of the materials used is given in Table 1.

Water-holding ability measured by centrifugation and by the dialysis bag method are shown in Table 2 for the 17 materials listed. No value could be obtained by centrifugation for most of the gel-forming polysaccharides because they did not centrifuge down under the prescribed conditions. Other preparations did not form a compact pellet on centrifugation, which made removal of the supernatant difficult. 
Table 1 Composition of fibre preparations $(\mathrm{g} / 100 \mathrm{~g}$ material)

\begin{tabular}{|c|c|c|c|c|c|c|c|c|c|c|c|}
\hline & \multirow{2}{*}{$\begin{array}{l}\text { Total } \\
\text { dietary } \\
\text { fibre }\end{array}$} & \multicolumn{3}{|c|}{ Non-cellulosic polysaccharides } & \multirow[b]{2}{*}{ d Cellulose } & \multirow[b]{2}{*}{ Lignin } & \multirow[b]{2}{*}{ Moisture } & \multirow[b]{2}{*}{ Ash } & \multirow[b]{2}{*}{ Protein } & \multirow[b]{2}{*}{ Starch } & \multirow[b]{2}{*}{$\mathrm{Fat}$} \\
\hline & & Hexose & Pentose & Uronic acid & & & & & & & \\
\hline \multicolumn{2}{|c|}{$\begin{array}{l}\alpha \text { Cellulose } \\
\text { SCMC } \\
\text { Locust bean gum }\end{array}$} & & & & & & $\begin{array}{r}3 \cdot 8 \\
11 \cdot 2 \\
10 \cdot 8\end{array}$ & $\begin{array}{r}0.4 \\
24 \cdot 0 \\
0.4\end{array}$ & & & \\
\hline $\begin{array}{l}\text { Guar gum } \\
\lambda \text { carrageenan } \\
\mathbf{K} \text { carrageenan }\end{array}$ & $86 \cdot 2$ & $82 \cdot 3$ & $2 \cdot 3$ & $\operatorname{Tr}$ & 1.0 & $\operatorname{Tr}$ & $\begin{array}{l}6 \cdot 8 \\
8 \cdot 6 \\
8 \cdot 2\end{array}$ & $\begin{array}{l}10 \cdot 2 \\
23 \cdot 8 \\
36 \cdot 5\end{array}$ & $3 \cdot 3$ & $\operatorname{Tr}$ & Tr \\
\hline Pectin & $85 \cdot 7$ & 15.6 & 6.6 & $63 \cdot 6$ & 0.0 & 0.0 & $10 \cdot 7$ & 1.0 & & & \\
\hline $\begin{array}{l}\text { Isogel } \\
\text { Normacol }\end{array}$ & $\begin{array}{l}81 \cdot 5 \\
62.0\end{array}$ & $15 \cdot 3$ & $55 \cdot 6$ & 6.0 & $4 \cdot 6$ & 0.0 & 7.9 & $\begin{array}{r}3.9 \\
15.9\end{array}$ & & $9 \cdot 8$ & \\
\hline $\begin{array}{l}\text { Normacol } \\
\text { Prewett's bran } \\
\text { Allinson's bran }\end{array}$ & $\begin{array}{l}62 \cdot 0 \\
48 \cdot 0 \\
30 \cdot 6\end{array}$ & $\begin{array}{l}6 \cdot 7 \\
7 \cdot 3\end{array}$ & $\begin{array}{l}24 \cdot 5 \\
13 \cdot 1\end{array}$ & $\begin{array}{l}4 \cdot 3 \\
2 \cdot 5\end{array}$ & $\begin{array}{l}8 \cdot 6 \\
4.9\end{array}$ & $\begin{array}{l}3.4 \\
2.8\end{array}$ & $\begin{array}{r}12 \cdot 2 \\
9 \cdot 4 \\
11 \cdot 2\end{array}$ & $\begin{array}{r}15 \cdot 2 \\
6 \cdot 4 \\
4 \cdot 0\end{array}$ & & & \\
\hline RHM bran & $60 \cdot 1$ & 9.9 & $29 \cdot 4$ & 1.4 & 12.9 & 6.5 & 4.6 & 7.4 & $14 \cdot 3$ & $12 \cdot 4$ & $\mathrm{Tr}$ \\
\hline Carrot & 66.9 & 11.6 & 10.9 & $19 \cdot 0$ & $25 \cdot 1$ & 0.4 & $5 \cdot 3$ & $8 \cdot 2$ & 10.5 & $\operatorname{Tr}$ & $\mathrm{Tr}$ \\
\hline Cabbage & $61 \cdot 1$ & $9 \cdot 7$ & $14 \cdot 2$ & $13 \cdot 3$ & $23 \cdot 4$ & 0.6 & $5 \cdot 3$ & $9 \cdot \overline{5}$ & $15 \cdot 1$ & 0.4 & $\mathrm{Tr}$ \\
\hline Apple & 87.6 & $29 \cdot 6$ & 7.8 & 15.8 & 31.9 & 2.5 & $4 \cdot 1$ & $5 \cdot 4$ & $5 \cdot 1$ & $\operatorname{Tr}$ & $\mathrm{Tr}$ \\
\hline $\begin{array}{l}\text { Bagasse } \\
\text { Potato pulp }\end{array}$ & $89 \cdot 5$ & & $28 \cdot 2^{*}$ & & $46 \cdot 4$ & $11 \cdot 2$ & $6 \cdot 3$ & 1.9 & & & \\
\hline Potato pulp & $56 \cdot 0$ & & & & & & 12.9 & $2 \cdot 2$ & & $28 \cdot 0$ & \\
\hline
\end{tabular}

Spaces indicate no value available.

Information for Guar gum, RHM bran, carrot, cabbage, and apple is from Cummings et al., 1978). Moisture and ash values for all remaining materials were determined as described in the text. Additional data for pectin is from Cummings et al. (1979), for bagasse from Morgan et al. (1974), for Isogel from Greenberg (1976), for Prewett's and Allinson's bran from Southgate et al. (1976), and for potato pulp from Dr Francis Wood, Unilever. The dietary fibre figure for Normacol is that given by the manufacturer as the \% sterculia in the preparation.

"Total non-cellulosic polysaccharides.

For the dialysis bag technique the water-holding values at 24 hours, 48 hours and after 24 hours with added PEG are shown. A negative value for PEG indicates that more water was removed from a bag containing a particular fibre preparation than from a control bag. About $15 \%$ of the bags developed holes over the three days and had to be discarded. This was probably caused by abrasion, as it was far more common with food materials. Repeat tests for these gave very similar results suggesting good reproducibility of the method. The coefficient of variation for triplicate analyses by the centrifugation technique was $4.1 \%$ and for uptake by the dialysis bag technique $9.8 \%$.

Table 2 Water-holding by centrifugation and dialysis bag methods ( $g$ water/g dry material)

\begin{tabular}{|c|c|c|c|c|}
\hline & \multirow[t]{2}{*}{ Centrifugation } & \multicolumn{3}{|c|}{ Dialysis bag } \\
\hline & & $24 h$ & $48 h$ & $+P E G$ \\
\hline $\begin{array}{l}\alpha \text { Cellulose } \\
\text { SCMC } \\
\text { Locust bean gum } \\
\text { Guar gum } \\
\lambda \text { Carrageenan } \\
\text { K Carrageenan } \\
\text { Pectin } \\
\text { Isogel } \\
\text { Normacol } \\
\text { Prewett's Bran } \\
\text { Allinson's bran } \\
\text { RHM Bran } \\
\text { Carrot } \\
\text { Cabbage } \\
\text { Apple } \\
\text { Bagasse } \\
\text { Potato pulp }\end{array}$ & $\begin{array}{l}6 \cdot 5 \\
* \\
13 \cdot 2 \\
* \\
11 \cdot 2 \\
* \\
* \\
26 \cdot 9 \\
19 \cdot 9 \\
7 \cdot 0 \\
3 \cdot 4 \\
8 \cdot 0 \\
22 \cdot 3 \\
18 \cdot 7 \\
38 \cdot 2 \\
8 \cdot 4 \\
9 \cdot 6\end{array}$ & $\begin{array}{r}5 \cdot 1 \\
44 \cdot 5 \\
19 \cdot 6 \\
21 \cdot 4 \\
41 \cdot 3 \\
36 \cdot 2 \\
56 \cdot 2 \\
12 \cdot 5 \\
8 \cdot 3 \\
6 \cdot 3 \\
7 \cdot 8 \\
4 \cdot 2 \\
11 \cdot 8 \\
8 \cdot 0 \\
12 \cdot 8 \\
5 \cdot 7 \\
7 \cdot 0\end{array}$ & $\begin{array}{r}5 \cdot 3 \\
60 \cdot 5 \\
26 \cdot 2 \\
27 \cdot 3 \\
54 \cdot 0 \\
46 \cdot 6 \\
80 \cdot 9 \\
17 \cdot 1 \\
13 \cdot 0 \\
10 \cdot 4 \\
12 \cdot 0 \\
8 \cdot 4 \\
24 \cdot 2 \\
15 \cdot 8 \\
27 \cdot 1 \\
7 \cdot 3 \\
11 \cdot 4\end{array}$ & $\begin{array}{r}0.0 \\
19 \cdot 1 \\
4.8 \\
4.6 \\
16.3 \\
10.9 \\
9.0 \\
2.2 \\
3.4 \\
-1 \cdot 1 \\
-0.7 \\
-0.3 \\
2.9 \\
1.8 \\
2.2 \\
-0.1 \\
1.6\end{array}$ \\
\hline
\end{tabular}

*No value obtainable.
A comparison of the results from centrifugation and dialysis bag uptake at 24 hours is shown in Fig. 1. This comparison excludes the gel-forming polysaccharides because of the problems which occurred with these on centrifugation. There is quite good agreement between the two methods $(r=0.85$, $\mathrm{n}=9$ ). Centrifugation values also correlated with water retention values with PEG $(r=0 \cdot 77, \mathrm{n}=9)$.

A comparison of the values for the dialysis bag method at 24 hours and after PEG showed a close relationship ( $r=0.87, n=17)$. This suggests that the properties which influence the amount of water that

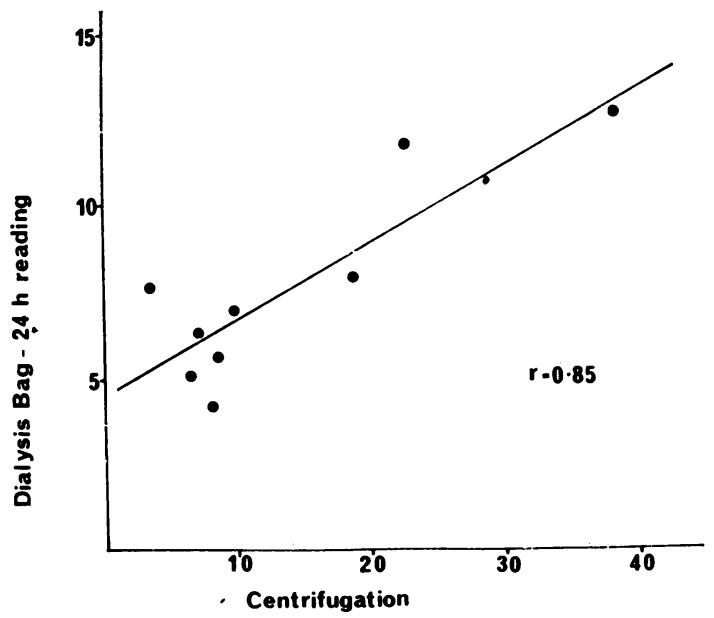

Fig. 1 Comparison of methods-uptake at 24 hours by the dialysis bag method and centrifugation. 
Table 3 Effect of particle size: water-holding by dialysis bag method for particle sizes 710-1000 $\mu \mathrm{m}$ and 75-150 $\mu \mathrm{m}$ ( $g$ water/g dry material)

\begin{tabular}{crrr}
\hline & $24 h$ & $48 h$ & $+P E G$ \\
\hline Isogel $(710-1000 \mu \mathrm{m})$ & 15.2 & 19.8 & 2.8 \\
$(75-150 \mu \mathrm{m})$ & 15.8 & 20.4 & 3.3 \\
Prewett's bran $(710-1000 \mu \mathrm{m})$ & 6.3 & 10.3 & -0.7 \\
$(75-150 \mu \mathrm{m})$ & 7.9 & 12.9 & -0.4 \\
Carrot $(710-1000 \mu \mathrm{m})$ & 13.4 & 26.1 & 2.7 \\
$(75-150 \mu \mathrm{m})$ & 17.2 & 29.5 & 2.7 \\
Cabbage $(710-1000 \mu \mathrm{m})$ & 7.0 & 13.8 & 1.7 \\
$(75-150 \mu \mathrm{m})$ & 10.7 & 19.6 & 1.7 \\
\hline
\end{tabular}

is taken up by the material also affect the amount of water which it will retain against an osmotic force.

\section{EFFECT OF PARTICLE SIZE}

The effect of different particle sizes on water holding was studied using four materials: Isogel, Prewett's wheat bran, cabbage, and carrot. The particle sizes used were those retained between the 710-1000 $\mu \mathrm{m}$ sieves and the 75-150 $\mu \mathrm{m}$ sieves. The smaller size was obtained by sieving then grinding the coarse material to the finer size and resieving. Results are given in Table 3. The water-holding at 24 hours was $28 \pm 10 \%$ greater at the smaller particle size per $g$ of material and, although these differences were not great, they did reach statistical significance $(t=$ 3.0618, $\mathrm{P}<0.05$ ).

\section{CHEMICAL STRUCTURE}

Using the dialysis bag method, the relationship between chemical composition and water holding was studied. To discount the effect of particle size, the materials were all used at the same size, 75-150 $\mu \mathrm{m}$, obtained by sieving and grinding where necessary.

The preparations used were: sodium carboxymethyl cellulose, cellulose, guar gum, locust bean gum, $\lambda$-carrageenan, and $\mathrm{K}$ carrageenan. The results are shown in Table 4. These materials were chosen to represent three pairs of polysaccharides which differed only slightly from each other in chemical

Table 4 Effect of chemical structure: water-holding by dialysis bag method for six pure polysaccharides at particle size 75-150 $\mu \mathrm{m}$ ( $\mathrm{g}$ water/g dry material)

\begin{tabular}{lrcc}
\hline & $24 h$ & $48 h$ & $+P E G$ \\
\hline$\alpha$ Cellulose & 4.4 & 6.1 & 0.3 \\
SCMC & 44.5 & 61.4 & 20.2 \\
K carrageenan & 33.4 & 45.9 & 10.9 \\
$\lambda$ carrageenan & 36.3 & 49.6 & 14.4 \\
Locust bean gum & 14.9 & 23.0 & 5.0 \\
Guar gum & 17.0 & 23.8 & 5.3 \\
\hline
\end{tabular}

structure. For locust bean gum/guar gum and the carrageenans, these differences produced only small changes in their ability to hold water. In the case of cellulose, however, the addition of the carboxymethyl group in the $\alpha$ cellulose led to a 10 -fold increase in water uptake.

RELATIONSHIP TO in vivo EFFECTS

Eight of the preparations-namely, cabbage, carrot, apple, guar gum and RHM bran, bagasse, Isogel, and pectin-had previously been fed to-human volunteers in controlled dietary studies in our own or other laboratories and reported in detail in the literature (Walters et al., 1975; Greenberg, 1976; Cummings et al., 1978; Cummings et al., 1979). The effect of these materials on faecal weight can therefore be compared with their ability to take up water. In order to make the data from the different studies comparable with respect to changes in faecal weight, the increases have been corrected to a $20 \mathrm{~g}$ dietary fibre intake. This assumes that fibre intake and change in faecal weight are linearly related over this range. The amount of preparation fed, the initial and final faecal weights and the ratio of final to initial corresponding to an intake of $20 \mathrm{~g}$ dietary fibre are given in Table 5. The relationship between the ratio and water uptake at 24 hours is shown in

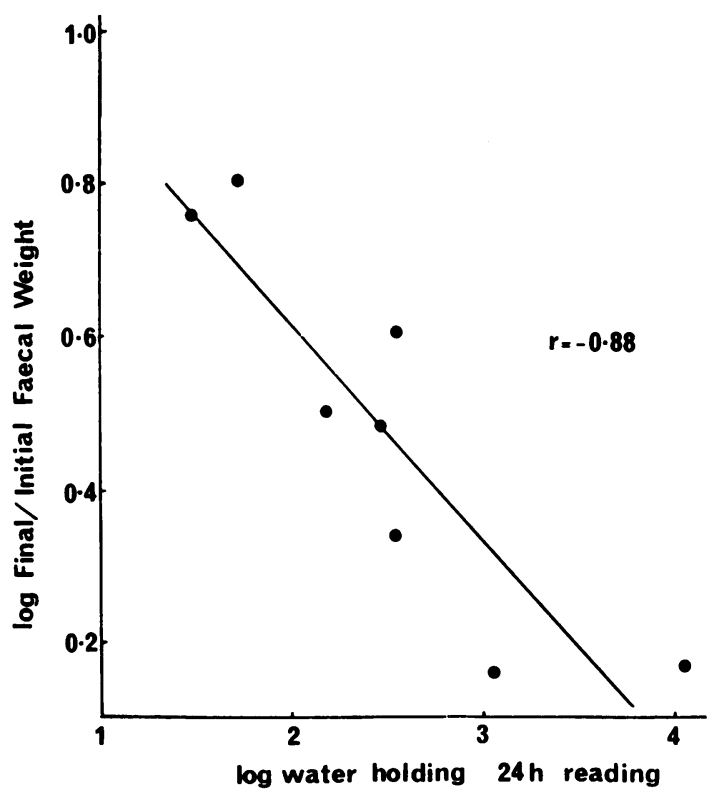

Fig. 2 The relationship between in vitro water-holding using the 24 hour value from the dialysis bag method (Table 2) and the ratio of final to initial faecal weight, corrected to $20 \mathrm{~g} \mathrm{DF}$. Materials, in order of increasing water holding are bran, bagasse, cabbage, carrot, Isogel, apple, guar, and pectin. 
Table 5 Published results from controlled diet studies for eight preparations

\begin{tabular}{|c|c|c|c|c|c|c|}
\hline Fibre preparation & $n$ & $\begin{array}{l}\text { Amount fed } \\
(\mathrm{g} / \text { day })\end{array}$ & $\begin{array}{l}\text { Dietary fibre fed } \\
(g / \text { day })\end{array}$ & $\begin{array}{l}\text { Initial faecal weight } \\
\pm S D(\text { g/day })\end{array}$ & $\begin{array}{l}\text { Final faecal weight } \\
\pm S D(g / \text { day })\end{array}$ & $\begin{array}{l}\text { Final initial for } \\
20 \mathrm{~g} \text { DF intake }\end{array}$ \\
\hline $\begin{array}{l}\text { Bran* } \\
\text { Bagasse† } \\
\text { Cabbage* } \\
\text { Carrot* } \\
\text { Isogel } \\
\text { Apple* } \\
\text { Guar* } \\
\text { Pectin \& }\end{array}$ & $\begin{array}{l}6 \\
9 \\
6 \\
6 \\
4 \\
6 \\
3 \\
5\end{array}$ & $\begin{array}{l}30 \\
10 \cdot 5 \\
30 \\
30 \\
25 \\
25 \\
20 \\
36\end{array}$ & $\begin{array}{r}18 \cdot 0 \\
9 \cdot 4 \\
18 \cdot 3 \\
20 \cdot 1 \\
20 \cdot 4 \\
21.9 \\
17 \cdot 2 \\
30 \cdot 8\end{array}$ & $\begin{array}{c}95 \cdot 5 \pm 21 \cdot 3 \\
88 \cdot 3 \pm 6 \cdot 49 \\
88 \cdot 2 \pm 23 \cdot 9 \\
117 \cdot 0 \pm 16 \cdot 8 \\
162 \cdot 0 \pm 43 \cdot 7 \\
141 \cdot 0 \pm 47 \cdot 9 \\
120 \cdot 3 \pm 35 \cdot 6 \\
107 \cdot 3 \pm 55 \cdot 0\end{array}$ & $\begin{array}{l}197 \cdot 0 \pm 32 \cdot 8 \\
139 \cdot 7 \pm 10 \cdot 29 \\
142.5 \pm 39.5 \\
188 \cdot 8 \pm 39 \cdot 4 \\
305 \cdot 5 \pm 153.3 \\
203 \cdot 2 \pm 70 \cdot 1 \\
139 \cdot 0 \pm 29 \cdot 1 \\
137.9 \pm 54.2\end{array}$ & $\begin{array}{l}2 \cdot 17 \\
2 \cdot 24 \\
1 \cdot 67 \\
1 \cdot 61 \\
1 \cdot 86 \\
1 \cdot 40 \\
1 \cdot 17 \\
1 \cdot 19\end{array}$ \\
\hline
\end{tabular}

*Cummings et al. (1978): †Walters et al. (1975): †Greenberg (1976): §Cummings et al. (1979).

$n=$ number of subjects

I \pm SEM

Fig. 2. This plot of the log data gives a significant inverse linear relationship $(r=0.88)$. Conversion of the water-holding values from uptake per gram of material to uptake per gram of dietary fibre does not affect this relationship $(r=0.87)$. Hence the greater the water-holding capacity of the dietary fibre fed, it would appear the less is the effect on faecal bulk.

\section{Discussion}

The capacity of different types of dietary fibre to take up and hold water has been used to explain their faecal bulking properties (Tainter and Buchanan, 1954; McConnell et al., 1974). This 'swelling power' of fibre, as it was originally known, was shown by Gray and Tainter (1941) to vary according to the type of fibre and to predict approximately the laxative effect of these materials. More recently, however, it has become clear that wheat bran, while holding only $3 \mathrm{~g}$ of water/g fibre, has pronounced faecal bulking properties (McConnell et al., 1974; Cummings et al., 1976), whereas pectin, which is able to hold 20 times as much water, has virtually no effect on faecal weight (Durrington et al., 1976; Kay and Truswell, 1978; Cummings et al., 1979).

These discrepancies in what seemed a valid hypothesis relating water-holding ability to faecal bulking led us to think that the method of measuring water-holding might be at fault.

Early attempts to measure water uptake used a measuring cylinder into which was placed a known amount of fibre and excess water (Klecker, 1931). The volume which the fibre achieved in the cylinder was read off at intervals. This simple method has a number of disadvantages. Water-soluble gums do not produce a clear line of demarcation between the water and material under test; lack of stirring favours compounds which do not cake, yet foodstuffs such as bran do not settle satisfactorily after stirring. An additional disadvantage is that it takes no account of the ability of the substance under test to hold on to water against the pull of the colonic absorptive forces. This was recognised by Blythe (1949) who placed the hydrated fibre on one side of a semipermeable membrane and a hypertonic solution (30\% PEG 4000) on the other. However, this method was also criticised on the basis that diffusion through the PEG solution was slow and changes at the membrane surface could not be adequately controlled. It also gave different results to those of the cylinder method. In 1974, McConnell et al., following the reawakening of interest in fibre, described an additional method for measuring water-holding in which the material was soaked in excess water for 24 hours and then centrifuged at $14000 \mathrm{~g}$ for one hour. The difference in weight between the original material and that of the pellet was ascribed to water-holding. This remains the easiest and most reproducible method, but it cannot be applied to gels and, like the other methods, does not in fact accurately predict in vivo faecal bulking, as we have shown.

The method described in this paper was an attempt to be more physiological by using a semipermeable membrance and a test fluid which resembled intestinal contents. PEG was again used to simulate the osmotic pull of the colonic absorptive surface. The method proved to be relatively easy to perform and reproducible, although there were problems with bags that became perforated. Because of the great amount of water taken up by some materials only small $(50 \mathrm{mg}$ ) quantities of fibre could be placed in the bag. This meant that all weighing had to be done with great accuracy and probably led to some overall loss of precision. The method was, however, applicable to all the materials under study.

The method produced a wide and continuous range of water uptake values for the 17 materials (Table 2) from $56.2 \mathrm{~g} / \mathrm{g}$ for pectin to $4.2 \mathrm{~g} / \mathrm{g}$ for RHM bran. Values at 48 hours were generally higher than at 24 hours but the ranking order did not change from the 24 hour value. The 24 hour 
values have therefore been preferred, as they gave a good guide to water uptake by the fibre preparation, 48 hours and any subsequent values providing additional information on whether maximum uptake has been achieved and the rate of uptake. Most differences between fibres, however, are clear at 24 hours.

The water-holding values after 24 hours with PEG indicate the ability of the fibre to retain water against an osmotic force. This property is important, as the human large bowel mucosa transports electrolytes such as sodium out of the bowel lumen against large electrochemical gradients, causing net absorption of water from the intestinal contents. The difficulty with this technique is in choosing an appropriate difference in osmolarity between the inside of the dialysis bag and the test fluid. Even with only 30 mosmol difference, half the preparations were unable to retain significant amounts of water, the food fibre preparations being notably unable to withstand this test. Human faecal water, however, has an osmolarity of $370 \mathrm{mosmol} / \mathrm{l}$ (Wrong et al., 1965) and values of as high as 475 have been reported (Tarlow and Thom, 1974) but these data are probably more a reflection of the poor diffusibility of solutes, particularly bacterial metabolites, which exists in the relatively solid left colonic contents than an indication of overall mucosal function.

The pure polysaccharides, most of which are gel forming, took up more water than the foodstuffs. Those which took up most-that is, pectin, SCMC and carrageenan-have charged or weakly ionic groups on the molecule unlike locust bean gum and guar gum. This suggests that a substantial part of their ability to retain water is based on the osmotic pull of counter-ions attracted to these charged groups. Here water uptake continues until the gel structure exerts sufficient elastic resistance to balance the osmotic pressure. This effect of charged groups is clearly seen from the data in Table 3 where the water-holding capacity of substances of similar basic structure are compared. The difference between SCMC and cellulose reflects both the ionic charge effect of the carboxymethyl group and also the way in which this substituent alters the ability of the cellulose molecules to pack together, form hydrogen bonds, and so reduce the space for water to be held. Comparison of $\lambda$ and $\mathrm{K}$ carrageenan also shows that small changes in substituent groups affect water uptake. $\lambda$ carrageenan has more sulphate groups and is thus more highly charged but, in addition, has less elastic resistance to water uptake, as its three-dimensional structure is a zig-zag ribbon in contrast with the helix of $\mathrm{K}$ carrageenan (Towle, 1977). The results for $\lambda$ carrageenan are therefore higher, although this is only significant after 48 hours. Similarly, the small change in side chain distribution between guar and locust bean gum leads to a difference in water uptake (Rol, 1973). Thus, both counter-ion attraction and the threedimensional structure of these compounds contribute to their ability to take up water.

In the food fibres the three-dimensional structure of the various polysaccharides is relatively fixed within the plant cell wall. Therefore the effect of charged groups is more dominant in determining water uptake. If the 24 hour uptake of food materials is plotted against uronic acid content the correlation is $0.87(n=6)$ and this relationship also holds for the PEG values $(r=0.92)$. Unlike McConnell et al. (1974), we found no relationship between the water-holding capacity and acid detergent fibre content $(r=0.05)$ but did find an inverse relationship with lignin content $(r=0.63)$. In addition, the pentose content of the non-cellulosic fraction of the fibre in these materials was inversely related to their ability to hold the water $(r=0.91)$.

Kirwan et al. (1974) noticed that particle size of foodstuffs influenced their water-holding capacity, in that large particles had greater water-holding ability. When, however, we took the same materials, ground them up and remeasured their water-holding there was a $28 \%$ increase at 24 hours, with no difference at all after PEG (Table 4). When these same materials were tested by the centrifugation technique the results predicted by Kirwan et al. were found except for Isogel. It therefore appears that the effect of particle size on water-holding depends on the method used to measure it. Centrifugation would tend to remove more water surrounding the particles, whereas uptake by the dialysis bag technique includes this. Which of these two situations relates more accurately to particles in the colon is hard to assess, and it is therefore difficult to extrapolate results from in vitro tests to what is happening in the gut.

A comparison of the results by centrifugation and the dialysis bag technique shows that the effect of particle size is the only divergence between the two methods. On the whole, materials behave in the same way with both, and a similar range of results is obtained. Of the two methods centrifugation is rather more precise and faster to perform than the dialysis bag technique, but the latter provides much more information. Many present investigations of dietary fibre are concerned with gel-forming polysaccharides (Jenkins et al., 1975) and it may be that the water-holding properties of these gels are important for their physiological effects. It is therefore an advantage to have a test where the waterholding of these materials can be determined.

What is clear from the present study is that, 
despite the use of two widely differing methods for measuring water-holding, neither technique gave results which predicted the in vivo bulking properties of the materials in the expected way. In fact, it appears that the greater the in vitro water-holding capacity the smaller is the effect on faecal weight. Either the hypothesis which relates water-holding to faecal bulking is wrong or needs modifying.

Several investigators have reported that, when dietary fibre is fed to human volunteers, a substantial part of it disappears during passage through the gut (Williams and Olmsted, 1936; Hoppert and Clark, 1945; Milton-Thompson and Lewis, 1971). This fact is notable, as it has been felt that fibre is inert and exerts its effect by purely physical means. It is now clear, however, that, as in animals, about $75 \%$ of ingested dietary fibre is digested in the gut. This process probably occurs in the human colon by the microflora which resemble those in the rumen in several respects (Bryant, 1974). The implication of these observations for the water holding theory of faecal bulking is two-fold. Either digestion in the gut totally destroys the capacity of fibre to hold water and therefore one must look for an alternative mechanism for fibre to exert its effect, through short chain fatty acid metabolism, for example (Helendoorn, 1978), or, secondly, the fibre that remains in the stool still does exert an effect on faecal bulk but its capacity to do this is dependent on how much survives digestion. In these circumstances the factors controlling the digestion of dietary fibre in the gut could be of importance.

We wish to thank Mr Will Branch for helpful discussion and assistance with water-holding methodology.

\section{References}

Bastedo, W. A. (1935). Foods and bulk producing drugs in the treatment of chronic constipation. Review of Gastroenterology, 2, 279-291.

Berger, F. M., Lugwig, B. J , and Wielich, K. H. (1953). The hydrophilic and acid binding properties of alginates. American Journal of Digestive Diseases, 20, 39-42.

Blythe, R. H,. Gulesich, J. J., and Tuthill, H. L. (1949). Evaluation of hydrophilic properties of bulk laxatives including the new agent, sodium carboxymethylcellulose. Journal of the American Pharmaceutical Association, 38, 59-64.

Bryant, M. P. (1974). Nutritional features and ecology of predominant anaerobic bacteria of the intestinal tract. American Journal of Clinical Nutrition, 27, 1313-1319.

Burkitt, D. P. (1971). Epidemiology of cancer of the colon and rectum. Cancer, 28, 3-13.

Cummings, J. H., Hill, M. J., Jenkins, D. J. A., Pearson, J. R., and Wiggins, H. S. (1976). Changes in fecal composition and colonic function due to cereal fiber. American Journal of Clinical Nutrition, 29, 1468-1473.
Cummings, J. H., Southgate, D. A. T., Branch, W., Houston, H., Jenkins, D. J. A., and James, W. P. T. (1978). Colonic response to dietary fibre from carrot, cabbage, apple, bran and guar gum. Lancet, 1, 5-9.

Cummings, J. H., Southgate, D. A. T., Branch, W., Wiggins, H. S., Houston, H., Jenkins, D. J. A., and Hill, M. J. (1979). The digestion of pectin in the human gut and its effect on calcium absorption and large bowel function. British Journal of Nutrition (in press).

Durrington, P. N., Manning, A. P., Bolton, C. H., and Hartog, M. (1976). Effect of pectin on serum lipids and lipoproteins, whole-gut transit-time and stool weight. Lancet, 2, 394-396.

Eastwood, M. A. (1973). Vegetable fibre: its physical properties. Proceedings of the Nutrition Society, 32, 137143.

Gray, H., and Tainter, M. L. (1941). Colloid laxatives available for clinical use. American Journal of Digestive Diseases, 8, 130-139.

Greenberg, C. J. (1977). Studies on the Fibre in Human Diets and its Effect on the Digestion and Absorption of Other Nutrients. PhD Thesis. University of Cambridge.

Helendoorn, E. W. (1978). Fermentation as the principal cause of the physiological activity of indigestible food residue. In Topics in Dietary Fiber Research, pp. 127-168. Edited by G. A. Spiller. Plenum Press: New York.

Hoppert, C. A., and Clark, A. J. (1945). Digestibility and effect on laxation of crude fiber and cellulose in certain common foods. Journal of the American Dietetic Association, 21, 157-160.

Ireson, J. D., and Leslie, G. B. (1970). An in vitro investigation of colloidal bulk-forming laxatives. Pharmaceutical Journal, 205, 540.

Ivy, A. C., and Isaacs, B. L. (1938). Karaya gum as a mechanical laxative. An experimental study on animals and man. American Journal of Digestive Diseases, 5, 315-321.

Jenkins, D. J. A., Leeds, A. R., Newton, C., and Cummings, J. H. (1975). Effect of pectin, guar gum and wheat fibre on serum cholesterol. Lancet, 1, 1116-1117.

Kay, R. M., and Truswell, A. S. (1977). Effect of citrus pectin on blood lipids and fecal steroid excretion in man. American Journal of Clinical Nutrition, 30, 171-175.

Kirwan, W. O., Smith, A. N., McConnell, A. A., Mitchell, W. D., and Eastwood, M. A. (1974). Action of different bran preparations on colonic function. British Medical Journal, 4, 187-189.

Klecker, E. (1931). Eine Methode zur Messung des Quellungsvermögens pharmakologisch verwendeter Quellstoffe. Archiv für experimentelle Pathologie und Pharmakologie, 161, 596-608.

Milton-Thompson, G. J., and Lewis, B. (1971). The breakdown of dietary cellulose in man (Abstract). Gut, 12, 853-854.

Monaco, A. L., and Dehner, E. J. (1955). An in vitro evaluation of some hydrophilic colloids as bulking agents. Journal of the American Pharmaceutical Association, 44, 237-241.

Morgan, B., Heald, M., Atkin, S. D., and Green, J. (1974). Dietary fibre and sterol metabolism in the rat. British Journal of Nutrition, 32, 447-455.

McConnell, A. A., Eastwood, M. A., and Mitchell, W. D. (1974). Physical characteristics of vegetable foodstuffs that could influence bowel function. Journal of the Science of Food and Agriculture, 25, 1457-1464.

Phillips, S. F., and Giller, J. (1973). The contribution of the colon to electrolyte and water conservation in man. Journal of Laboratory and Clinical Medicine, 81, 733-746. Rol, F. (1973). Locust bean gum. In Industrial Gums, 2nd 
ed., pp. 323-335. Edited by R. L. Whistler and J. N. Bemiller. Academic Press: New York.

Southgate, D. A. T., Bailey, B., Collinson, E., and Walker, A. F. (1976). A guide to calculating intakes of dietary fibre. Journal of Human Nutrition, 30, 303-313.

Tainter, M. L., and Buchanan, O. H. (1954). Quantitative comparisons of colloidal laxatives. Annals of the New York Academy of Sciences, 58, 438-454.

Tarlow, M. J., and Thom, H. (1974). A comparison of stool fluid and stool dialysate obtained in vivo. Gut, 15, 608-613.

Towle, G. A. (1973). Carrageenan. In Industrial Gums, 2nd ed., pp. 83-114. Edited by R. L. Whistler and J. N. Bemiller. Academic Press: New York.
Trowell, H. (1972). Ischaemic heart disease and dietary fibre. American Journal of Clinical Nutrition, 25, 926-932.

Walters, R. L., McLean-Baird, I., Davies, P. S., Hill, M. J., Drasar, B. S., Southgate, D. A. T., Green, J., and Morgan, B. (1975). Effects of two types of dietary fibre on faecal steroid and lipid excretion. British Medical Journal, 2, 536-538.

Williams, R. D., and Olmsted, W. H. (1936). The manner in which food controls the bulk of the feces. Annals of Internal Medicine, 10, 717-727.

Wrong, O., Metcalfe-Gibson, A., Morrison, R. B. I., Ng, S. T., and Howard, A. V. (1965). In vivo dialysis of faeces as a method of stool analysis. I. Technique and results in normal subjects. Clinical Science, 28, 357-375. 